\title{
Comparative study on microhardness between friction stir welding and tungsten inert gas assisted friction stir welding of pure copper
}

\author{
Marius Adrian Constantin 1,*, Ana Boșneag ${ }^{1}$, Eduard Niţu ${ }^{2}$ and Monica Iordache $^{2}$ \\ ${ }^{1}$ University Politehnica of Bucharest, Machine Building Technology Department, Splaiul \\ Independenţei Street No. 313, Bucharest, Romania \\ ${ }^{2}$ University of Piteşti, Manufacturing and Industrial Management Department, Târgul din Vale Street \\ No.1, Pitești, Romania
}

\begin{abstract}
Welding copper and its alloys is usually difficult to achieve by conventional fusion welding processes because of high thermal diffusivity of copper, which is at least 10 times higher than most steel alloys. In order to reduce the increased temperature loss, it would be advantageous to use a process that is carried out at lower temperatures. Friction Stir Welding (FSW) is a solid state joining process that involves the joining of two metal pieces at the molecular level without melting and was explored as a feasible welding process. In order to achieve an increased welding speed and a reduction in tool wear, this process is assisted by another one (TIG tungsten inert gas) which generates and adds heat to the process. The research includes two experiments for the FSW process and two experiments for TIG assisted FSW process. It is presented the evolution of the temperature and of the axial force during the process and is determined the microhardness for each experimental case. The aim of this paper is to make known the effects of using TIG assisted FSW process on the microhardness of the pure copper joints and to present some conditions in which it is less affected.
\end{abstract}

\section{Introduction}

Friction Stir Welding is a solid state joining process that relies on frictional heating and plastic deformation realised by a non-consumable welding tool that is rotating on the contact surfaces of the workpieces. The welding tool is positioned perpendicularly on the material and is moving with the welding speed along the joint line. The plasticized material is transferred behind the tool, forming a welded joint, figure 1. TIG assisted FSW is a development of the FSW process, causing the emergence of a hybrid welding process, in the same solid form, which integrates the preheating of plates by the TIG process [1].

The microhardness of FSW welded joints is the most analysed mechanical property in the scientific papers. This is due, on one hand, to the fact that microhardness depends on the microstructural changes, the grain size and the precipitation state generated by the welding

\footnotetext{
${ }^{*}$ Corresponding author: constantin_marius.adrian@yahoo.com
} 
process, and on the other hand, because there is a good correlation between the microhardness profile and the profile of the other mechanical properties (Rp0.2, Rm, A\%) [2], this correlation makes from the microhardness a marker of mechanical properties. Research in this field has shown that increasing the heat input for cooper alloys leads to annealing softening and lower hardness. Lowering the heat input leads to refined grain size and eventually to equal or even higher hardness of the welds as compared to the base material $[3,4]$.

\section{Experimental procedure}

The experimental stand includes a FSW welding machine (FSW 4-10), a TIG welding head, an orientation and fixing device and various data acquisition, recording and monitoring systems. Welding processes are monitored by analysing the temperature and axial force recorded values throughout the process.
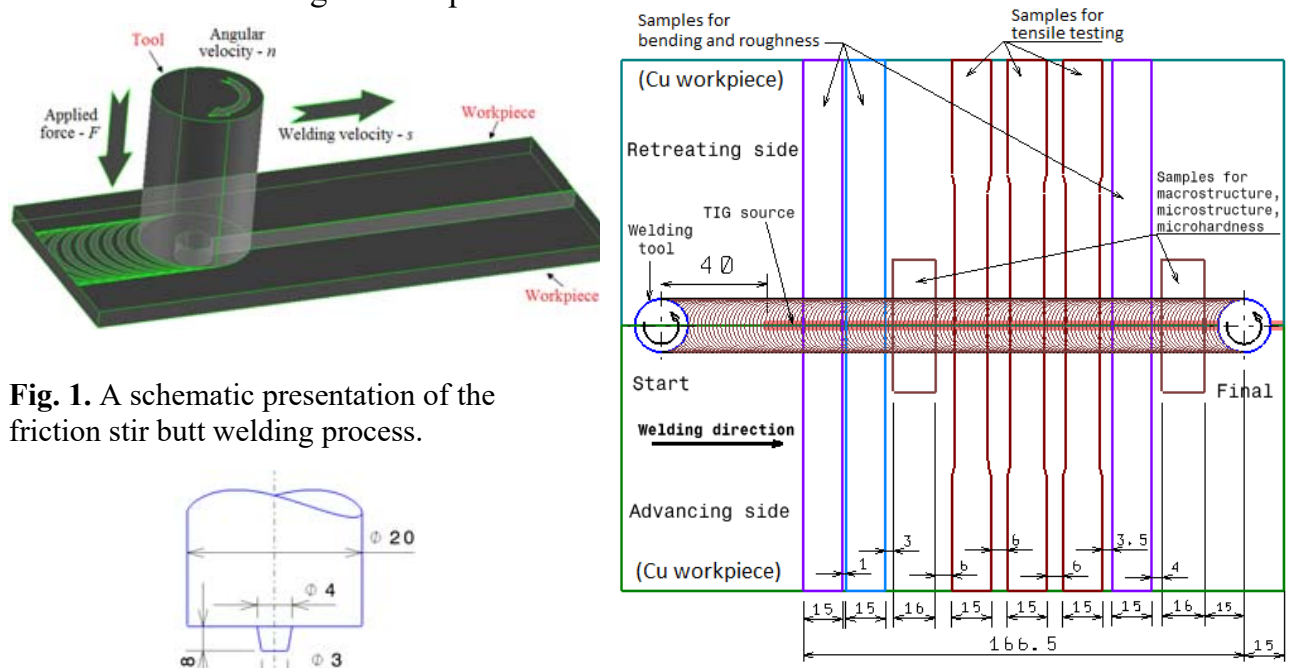

Fig. 1. A schematic presentation of the friction stir butt welding process.

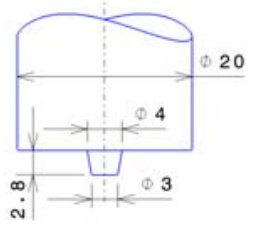

Fig. 3. The relative position of the specimens used to

Fig. 2. Geometry and dimensions of the welding tool. determine microhardness.

The chemical composition and the effective mechanical properties of the Cu-DHP (phosphorus - deoxidized copper) sheets used in the experimental program are provided in Tables 1 and 2 (EN 1652). Copper has a face-centred cubic (fcc) crystal structure and it doesn't undergo phase changes after solidification. The melting point of copper is $1084^{\circ} \mathrm{C}$.

Table 1. Chemical composition of $\mathrm{Cu}-$ DHP.

\begin{tabular}{|c|c|}
\hline Alloying element & Percentage [\%] \\
\hline $\mathrm{Cu}$ & 99,9 \\
\hline $\mathrm{P}$ & $0,015-0,04$ \\
\hline
\end{tabular}

Table 2. Mechanical characteristics of $\mathrm{Cu}-$ DHP.

\begin{tabular}{|l|c|}
\hline Name of the characteristic & Value \\
\hline Tensile strength, Rm & $260 \mathrm{MPa}$ \\
\hline Vickers hardness, HV0,3 & $81 \mathrm{HV} 0,3$ \\
\hline Elongation, A5 & $40 \%$ \\
\hline
\end{tabular}

For butt welding $\mathrm{Cu}$-DHP sheets were developed experiments using FSW and TIG assisted FSW processes, Table 3. The process parameters which varied were the welding speed $[\mathrm{mm} / \mathrm{min}]$ and the axial force $[\mathrm{KN}]$ which was manually adjusted until a value that presented a suitable visual aspect of the joint, while the rotational speed of the tool [rpm] and the current intensity of the TIG source [A] remained constant. The workpieces have a dimension of $250 \times 100 \times 3$ [mm], being cut having the same rolling direction, parallel to the 
side on which the joint will be made. The used welding tool has a classical mono-block structure with conical pin and it is made of P20+S (carbide of sintered tungsten), figure 2.

Table 3. Experimental plan of FSW and TIG assisted FSW processes and average values measured for axial force and for temperature.

\begin{tabular}{|c|c|c|c|c|c|}
\hline $\begin{array}{l}\text { Exp. } \\
\text { Cod. }\end{array}$ & $\begin{array}{c}\text { Rotational } \\
\text { speed [rpm] }\end{array}$ & $\begin{array}{l}\text { Welding speed } \\
{[\mathrm{mm} / \mathrm{min}]}\end{array}$ & $\begin{array}{l}\text { TIG welding } \\
\text { current [A] }\end{array}$ & $\begin{array}{c}\text { Average axial } \\
\text { force }[\mathrm{KN}]\end{array}$ & $\begin{array}{c}\text { Average } \\
\text { temperature }\left[{ }^{\circ} \mathrm{C}\right]\end{array}$ \\
\hline 1.7 & \multirow{4}{*}{1000} & 120 & \multirow[t]{2}{*}{-} & 9.1 & 530 \\
\hline 1.8 & & 120 & & 11.6 & 663 \\
\hline 2.3 & & 250 & \multirow[t]{2}{*}{100} & 11.7 & 868 \\
\hline 2.4 & & 350 & & 12 & 845 \\
\hline
\end{tabular}

From the welded joints, samples were cut for macroscopic and microscopic analysis, for measurement of microhardness and roughness, but also for tensile and bending testing. This paper presents and analyses the results regarding the distribution of temperature, axial force and microhardness values resulted from the experiments. The samples for microhardness analysis were cut from the beginning and from the end of the joint to highlight how microhardness is affected by process stability, figure 3 .

\section{Results and discussions}

\subsection{Temperature and axial force analysis}

The temperature and the axial force were represented on the same diagram, having as background the specimen sampling scheme to highlight the local conditions in which the joining was made figures 4-6.

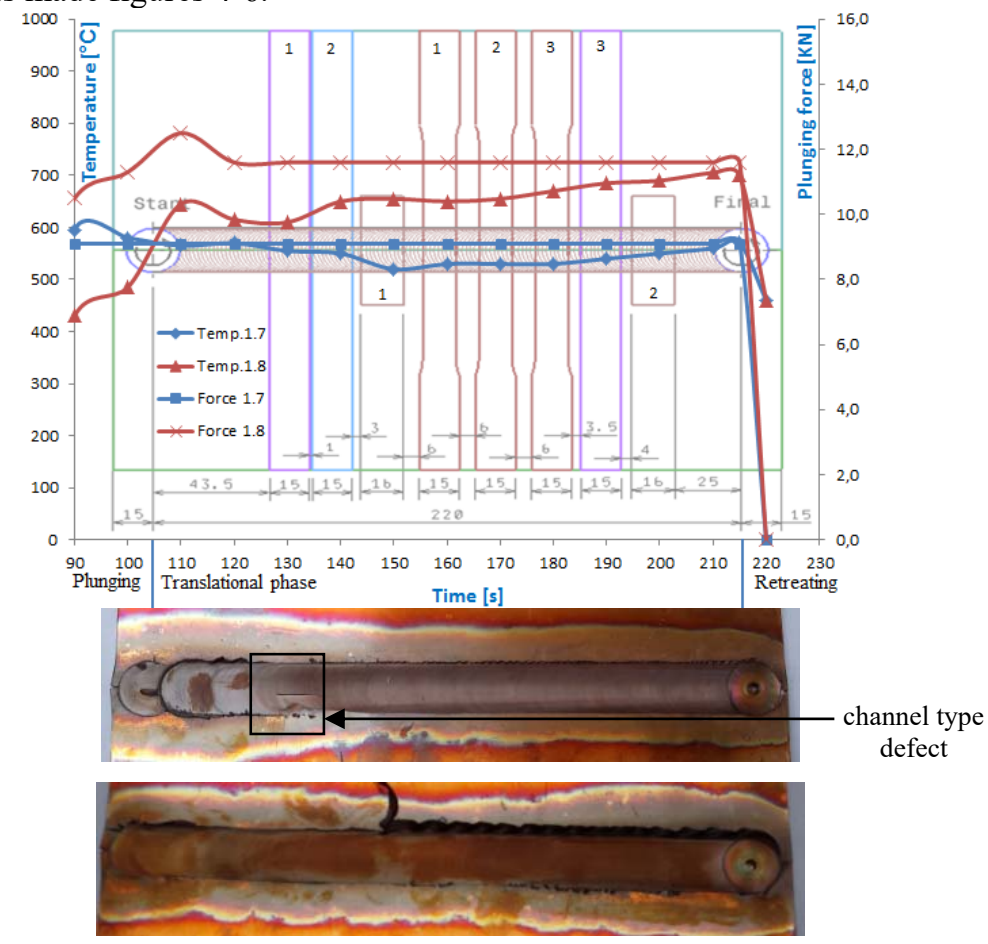

Fig. 4. Experiments 1.7 and 1.8: (a) evolution of the temperature and of the axial force during FSW process; (b) Exp.1.7 - welded joint; (c) Exp.1.8 - welded joint. 


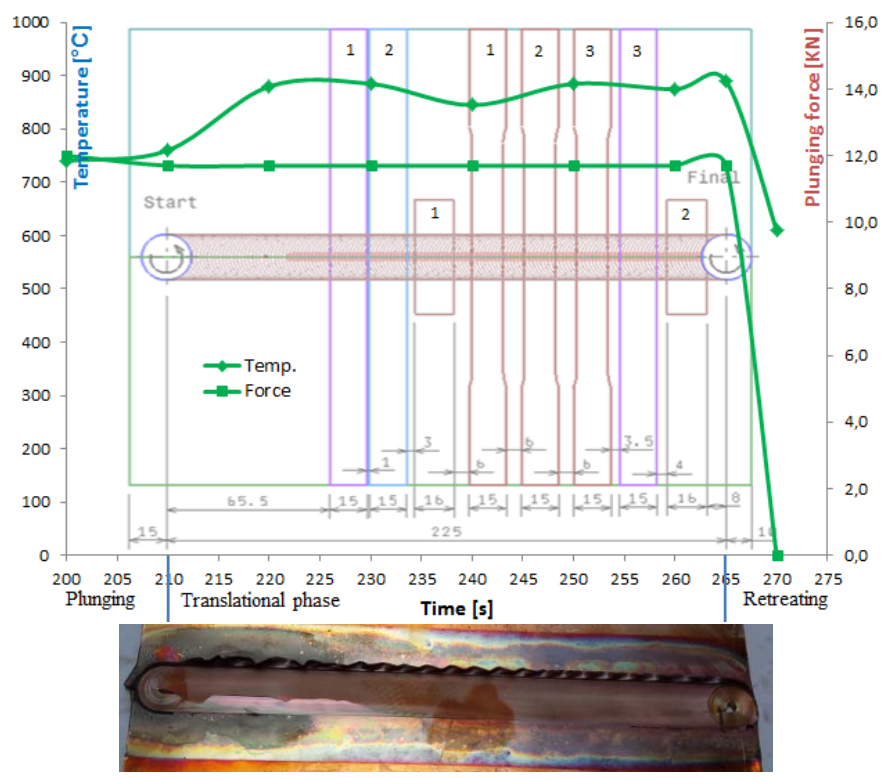

Fig. 5. Experiment 2.3 (a) evolution of the temperature and of the axial force during TIG assisted FSW process; (b) welded joint.

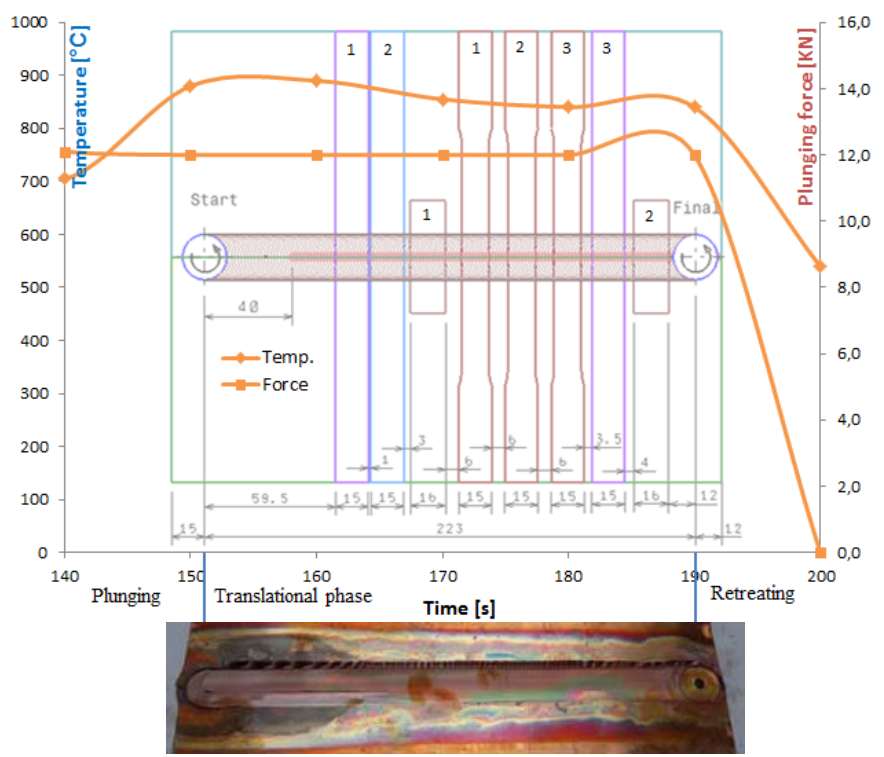

Fig. 6. Experiment 2.4 (a) evolution of the temperature and of the axial force during TIG assisted FSW process; (b) welded joint.

The analysis of the temperature and axial force evolution presented in previous diagrams highlights the following aspects:

- If we perform a comparative analysis between experiments 1.7 and 1.8 we notice that these two experiments present almost the same process parameters. The only difference between these two experiments is given by the recorded axial force, which is higher for exp. 1.8. This difference leads to an increased recorded temperature during this experiment, figure 4. Also for experiments 2.3 and 2.4 it is observed that the value of the temperature 
increases with the decrease of the welding speed. The highest temperature was found, as expected, in TIG assisted FSW process, Table 3.

- The axial force must have a value that assures a certain penetration of the tool in the welding materials in order not to cause channel defects (insufficient plunging, figure 4,b) or excessive burr (too much plunging, figure 4,c). Thus, for the presented experimental case, the value of the force must be included in the range 10-11 [KN].

\subsection{Microhardness analysis}

Microhardness profiles were measured over the transverse cross-section of Cu-DHP FSW welds with hot-rolled base material, figure 7. From each joint were extracted two samples, one from the beginning of the joint and the other from the end, figure 3. Subsequently these samples have been subjected to an automatic grinding and polishing.

The microhardness was measured with an electronic microhardness tester, type InnovaTest Falcon 500. The Vickers microhardness values of the welded specimens were determined under the load of $300 \mathrm{~g}$ during $10 \mathrm{~s}$ of penetration time.

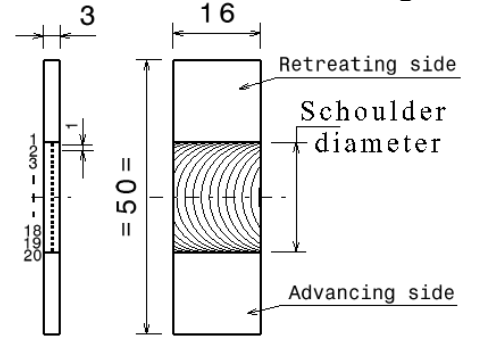

Fig. 7. The location of points selected for the microhardness measurement test.

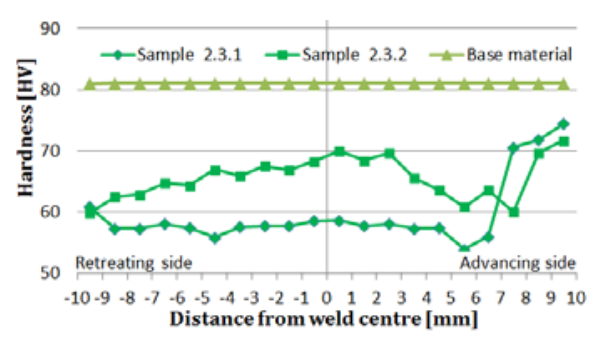

Fig. 9. Measured microhardness profile of Experiment 2.3.

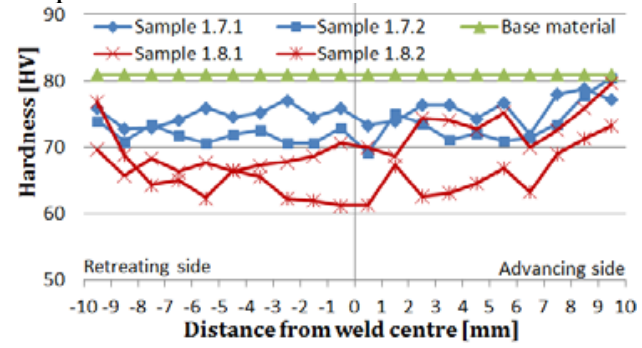

Fig. 8. Measured microhardness profiles of Experiments 1.7 and 1.8.

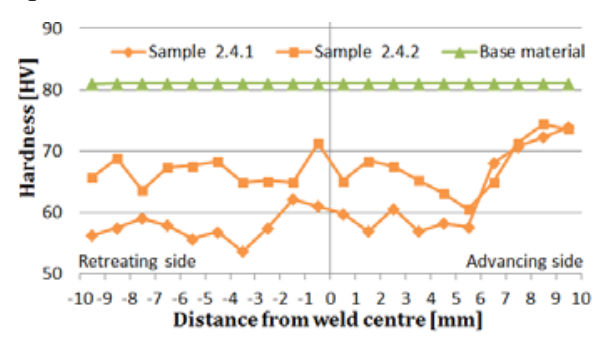

Fig. 10. Measured microhardness profile of Experiment 2.4.

The weld's hardness depends on the state in which the base material is found (annealed or work-hardened) as well as the heat input generated in the process. Two competitive mechanisms influence the hardness of copper FSW welds: anneal softening and grain refinement. Increasing the heat input leads to annealing softening and lower hardness, figures 8-10. So, the lowest values of the hardness were identified for the hybrid process. Lowering the heat input leads to refined grain size and approximately equal hardness of the welds as compared to the base material, figure 8 .

Regarding the evolution of microhardness profile according to the local conditions registered on the samples, are ascertained the following:

- In experiments 1.7 and 1.8, the values measured on the sample taken from the beginning of the joint are slightly higher than those measured on the sample taken from the end of the joint, figure 8 . This is explained by the temperature's differences in these two areas, lower in the beginning and higher in the end, figure 4. 
- In experiments 2.3 and 2.4, the values measured on the sample taken from the beginning of the joint are lower than those measured on the sample taken from the end of the joint, figures 9,10 . Although the temperature's values in the two areas are approximately equal or even bigger for the samples taken from the end of the joint, figures 5,6. These differences can be attributed to different cooling rates (at the end of the process, the additional TIG heat input being interrupted). This behaviour of copper is also identified in other scientific papers, in which the TIG assisted FSW joints have undergone forced cooling [5].

From the analysis of the eight microhardness profiles it is also found that the average value of the microhardness measured on the advancing side is higher than those measured on the retreating side, Table 4 . Thus, it can be deduced that lower temperatures are recorded on the advancing side than on the retreating side.

Table 4. Average values of microhardness.

\begin{tabular}{|c|c|c|c|c|}
\hline $\begin{array}{c}\text { Exp. } \\
\text { Cod. }\end{array}$ & $\begin{array}{c}\text { Sample } \\
\text { No. }\end{array}$ & $\begin{array}{c}\text { Average hardness on } \\
\text { retreating side [HV] }\end{array}$ & $\begin{array}{c}\text { Average hardness on } \\
\text { advancing side [HV] }\end{array}$ & $\begin{array}{c}\text { Average hardness on } \\
\text { experiment [HV] }\end{array}$ \\
\hline \multirow{2}{*}{1.7} & 1.7 .1 & 74,91 & 75,70 & \multirow{2}{*}{74,02} \\
\cline { 2 - 4 } & 1.7 .2 & 71,96 & 73,53 & \\
\hline \multirow{2}{*}{1.8} & 1.8 .1 & 67,87 & 73,33 & \multirow{2}{*}{68,26} \\
\cline { 2 - 4 } & 1.8 .2 & 65,54 & 66,29 & \multirow{2}{*}{62,69} \\
\hline 2.3 & 2.3 .1 & 57,84 & 61,59 & \multirow{2}{*}{63,87} \\
\cline { 2 - 4 } & 2.3 .2 & 65,01 & 66,33 & \\
\hline \multirow{2}{*}{2.4} & 2.4 .1 & 57,76 & 63,50 & 67,44 \\
\cline { 2 - 4 } & 2.4 .2 & 66,80 & & \\
\hline
\end{tabular}

\section{Conclusions}

As a result of the researches carried out, the following main conclusions are presented:

1) In both processes the temperature increases with increasing the axial force and with decreasing welding speed.

2) The highest values of microhadness were determined for experiment 1.7, the experiment with the lowest temperature, performed using the FSW classic process.

3) The advancing side of the joint presents a slight increase in microhardness, which is attributed to the generation of a lower temperature on that side.

4) Using a supplementary heat source allows an increasing in welding speed at speeds more than twice as big as in FSW processes, but also brings some disadvantages to the properties of the welded joint, such as the decrease in the microhardness of the join.

On future researches, this study will be extended to a larger set of parameters and it will be analysed the cooling effect on properties of TIG assisted FSW joining for pure copper plates, because this hypothesis presents a promising way to develop a hybrid FSW process that has both high productivity and good mechanical properties of the joint.

The work was done with the support of the National Institute for Welding and Material Testing, ISIM Timişoara.

\section{References}

1. R. Cojocaru, C. Ciucă, L. Boțilă, V. Verbițchi, Welding \& Material Testing, 4-8 (2015)

2. K. Surekha, A. Els-Botes, Materials and Design 32, 911-916 (2011)

3. G.M. Xie, Z.Y. Ma, L. Geng, Scripta Materialia 57, 73-76 (2007)

4. G. Cam, International Materials Reviews 56, 1-48 (2011)

5. K.P. Mehta, V.J. Badheka, J. of Materials Processing Technology 239, 336-345 (2017) 